\title{
Marine-friendly Antifouling Coating Based on the Use of a Fatty Acid Derivative as a Pigment
}

\author{
Rafael S. Peres ${ }^{\mathrm{a} *}$, Alessandra F. Baldissera ${ }^{\mathrm{a}}$, Elaine Armelin ${ }^{\mathrm{b}, \mathrm{c}}$, Carlos Alemán ${ }^{\mathrm{b}, \mathrm{c}}$, Carlos A. Ferreira $^{\mathrm{a}}$ \\ ${ }^{a}$ Laboratório de Materiais Poliméricos - LaPol, Programa de Pós-graduação em Engenharia de Minas, \\ Metalúrgica e de Materiais - PPGE3M, Universidade Federal do Rio Grande do Sul - UFRGS, \\ Av. Bento Gonçalves, 9500, CEP 91501-970, Porto Alegre, RS, Brazil \\ ${ }^{\mathrm{b}}$ Departament d'Enginyeria Química, ETSEIB, Universitat Politècnica de Catalunya, \\ Av. Diagonal 647, 08028 Barcelona, Spain \\ ${ }^{\mathrm{c}}$ Centre for Research in Nano-Engineering, Universitat Politècnica de Catalunya, Campus Sud, \\ Edifici C', C/Pasqual $i$ Vila s/n, Barcelona E-08028, Spain
}

Received: September 10, 2013; Revised: January 22, 2014

\begin{abstract}
This study was devoted to examining the application of copper dodecanoate as a non-contaminant antifouling pigment due to its low copper content and fatty acid nature. For this purpose, antifouling paints with mono-component epoxy resin and rosin matrixes were formulated, and their antifouling efficiency was evaluated. Before its incorporation into the different formulations, the synthesized pigment was characterized. Immersion tests in a marine environment were carried out for 12 months to evaluate the antifouling efficiency of the developed paints; the results were compared with those from a commercial paint. The antifouling efficiency of the new epoxy formulation was found to be considerably higher than that of the rosin formulation and very similar to that of the commercial paint Most importantly, the release of copper from the epoxy paint formulated with copper dodecanoate was $73.5 \%$ lower than that of the commercial paint, suggesting prolonged activity of the developed paint.
\end{abstract}

Keywords: antifouling paints, copper dodecanoate, low copper content

\section{Introduction}

All structures immersed in a marine environment are subject to the deposition of several organisms such as barnacles, mussels, algae and others. Marine fouling is the result of the growth of these plants and animals on the surface of submerged objects ${ }^{1}$. The presence of fouling has a great impact on the naval industry due to the negative influence on the performance, durability and maintenance of mobile or stationary submerged structures ${ }^{2-4}$. Arai ${ }^{5}$ estimated that fuel consumption increases by around $6 \%$ per $100 \mathrm{~mm}$ of average roughness caused by fouling attached to ship surfaces. Other relevant factors are the risk of localized corrosion due to the metabolic activity of the attached organisms and the obstruction of turbines in hydroelectric plants ${ }^{6}$.

Since the beginning of the history of navigation, many materials have been used in order to minimize the fouling problem. However, the development of antifouling paints began only in the mid of $1800 \mathrm{~s}^{7}$. Currently, the use of antifouling paints is the most economical and satisfactory method to protect submerged structures ${ }^{8}$. Generally, antifouling paints contain biocide pigments against the fouling organisms in their formulation. However, the release mechanism of these pigments can vary with the type of paint matrix. There are three types of matrix: insoluble, soluble and self-polishing?.

In the past, toxic biocide pigments such as arsenic and mercury compounds were incorporated into antifouling

*e-mail: rafael.s.peres@gmail.com coatings. In recent decades, the most commonly used antifouling agents have contained the tributyltin (TBT) moiety, which combined with the new technology of self-polishing resins has shown excellent performance against fouling ${ }^{4,10,11}$. However, these pigments have caused disastrous effects to the environment, as TBT is considered one of the most toxic compounds released into the aquatic environment ${ }^{12,13}$. The first effects of TBT were documented in the late 1970s in France. The extreme toxicity of TBT affected the growth of oysters and other mollusks at concentrations of $20 \mathrm{ng} \mathrm{L}^{-1}$ and less than $10 \mathrm{ng} \mathrm{L}^{-1}$, respectively ${ }^{14}$. At the present time, TBT and other tin-based antifouling agents are banned by the International Marine Organization (IMO) $)^{15}$.

TBT-free formulations, in which tin is replaced by metals like copper ${ }^{5,8,16}$ zinc $^{17}$ and titanium ${ }^{18}$, are in use today. Although copper is essential for all forms of life due to cellular processes, it is considered toxic when tolerance limits are exceeded ${ }^{19}$. Copper has excellent antifouling properties against barnacles and algae, even though some species are resistant to this metal ${ }^{20}$. Together with copper, other toxic biocides such as copper thiocyanate, zinc pyrithione, Diuron $®$ (3-(3',4'-dichlorophenyl)-1,1dimethylurea) and Irgarol@ 1051 (2-(tert-butylamino)-4cyclopropylamino)-6-(methylthio)-1,3,5-triazine) are used to increase the efficiency of antifouling coatings ${ }^{20}$.

A fatty acid (FA) is a carboxylic acid with a long aliphatic chain (between 10 and 28 carbon atoms), which 
is either saturated or unsaturated ${ }^{21}$. The bioactivities of FAs from a wide range of biological sources, including algae, animals and plants have been reported in the literature. According to a recent review by Desbois et al. ${ }^{21}$, anti-algal, antibacterial, anti-fungal, anti-protozoan and other activities have been attributed to many FAs. Dodecanoic acid or lauric acid is a saturated fatty acid (C12:0) that occurs as a major compound in coconut oil, palm kernel oil and cinnamon oil ${ }^{22,23}$. Glycerides rich in lauric acid are used in the food and chemical industries for the production of flavorings and surfactants, respectively ${ }^{23}$. Wu et al. ${ }^{24}$ have demonstrated the anti-algal properties of dodecanoic acid, while Bergsson et al..$^{25,26}$ have reported antibacterial and anti-fungal properties.

The aim of this study was to evaluate the efficiency of the use of copper dodecanoate as a low copper content and fatty acid derivative antifouling pigment. For this purpose, the compound was synthesized and characterized. Subsequently, antifouling paints were formulated using a synthetic epoxy resin and rosin, a natural resin. The antifouling efficiency of the copper dodecanoate-containing paints was compared with that of commercially available coatings. Furthermore, the influence of the antifouling pigment concentration on such efficiency was examined. Finally, the environmental advantages of the formulated paints were investigated by evaluating the release of copper.

\section{Experimental Procedure}

\subsection{Materials}

The synthesis of copper dodecanoate was carried out using dodecanoic acid (Across, USA), $\mathrm{CuSO}_{4} \cdot 5 \mathrm{H}_{2} \mathrm{O}$ (Vetec, Brazil), $\mathrm{NaOH}$ (Synth, Brazil) and ethanol (Vetec, Brazil). The materials used for the rosin solubility and copper release tests were $\mathrm{NaCl}, \mathrm{NaOH}, \mathrm{MgCl}_{2} \cdot 6 \mathrm{H}_{2} \mathrm{O}, \mathrm{SrCl}_{2} \cdot 6 \mathrm{H}_{2} \mathrm{O}$, $\mathrm{NaHCO}_{3}, \mathrm{H}_{3} \mathrm{BO}_{3}, \mathrm{NaF}$ (all from Vetec, Brazil), $\mathrm{Na}_{2} \mathrm{SO}_{4}$, $\mathrm{CaCl}_{2}, \mathrm{KCl}$ and $\mathrm{KBr}$ (all from Synth, Brazil). All solutions were prepared with analytical grade reagents.

Coatings were prepared using methyl ethyl ketone (MBN chemicals, Brazil) as the solvent, $\mathrm{TiO}_{2}$ and chalk (Polimerum, Brazil) as pigments, disperbyk-2070 as the dispersing agent, BYK-410 (BYK-Chemie GmbH, Germany) as a rheological additive, mono-component epoxy resin solution Araldite GZ 488N40 BR-1 (Aralsul, Brazil) and WW rosin (RB Sul, Brazil).

The commercial antifouling coating Intermarine (Akzo Nobel, USA) was used as a reference to control the antifouling activity and the two-component epoxy primer Intergard 269 (Akzo Nobel, USA) was used as an anticorrosive primer.

\subsection{Copper dodecanoate pigment preparation and characterization}

The synthetic procedure reported by Lisboa et al. ${ }^{27}$ was used for the synthesis of copper dodecanoate, with some modifications. A quantity of $20 \mathrm{~g}$ of dodecanoic acid was dissolved in $120 \mathrm{~mL}$ of ethanol and then neutralized with $4 \mathrm{~g}$ of $\mathrm{NaOH}$ (previously dissolved in $100 \mathrm{~mL}$ of ethanol). After precipitation, the solid was placed in a funnel with filter paper and washed with $100 \mathrm{~mL}$ of ethanol. The solid was dried and then dissolved in $100 \mathrm{~mL}$ of deionized water. After total dissolution, $100 \mathrm{~mL}$ of a $12.5 \%(\mathrm{w} / \mathrm{v})$ solution of $\mathrm{CuSO}_{4} \cdot 5 \mathrm{H}_{2} \mathrm{O}$ was slowly added with vigorous stirring. After the addition, the reaction was stirred for three hours. At the end of the reaction, the solid was filtered in a Büchner funnel and dried for 12 hours at $60^{\circ} \mathrm{C}$. A light blue pigment was obtained.

The synthesized pigment was characterized by FTIR spectroscopy, thermal analysis and X-ray diffraction (XRD). The FTIR spectrum was recorded using a Perkin Elmer Spectrum 1000 spectrometer with $\mathrm{KBr}$ pellets. Thermal properties were examined by differential scanning calorimetry (DSC, TA instruments DSC 2010 Q20) and thermogravimetric analysis (TGA, TA Instruments TGA 2050). DSC experiments were carried out using approximately $5 \mathrm{mg}$ samples heated in flowing nitrogen or air (flow rate $50 \mathrm{~mL} / \mathrm{min}$ ) at a heating rate of $10^{\circ} \mathrm{C} / \mathrm{min}$. TGA analyses were performed with approximately $20 \mathrm{mg}$ of samples heated at a scan rate of $20^{\circ} \mathrm{C} / \mathrm{min}$ in a nitrogen atmosphere. XRD analyses were performed with a Bruker D8 Advance diffractometer using $\mathrm{Cu} \mathrm{K} \alpha$ radiation. A step size of $0.02^{\circ}$ was used to create X-ray patterns to identify the material at a $2 \theta$ angle $\left(2^{\circ}-30^{\circ}\right)$.

\subsection{Rosin solubility and copper release tests}

In order to evaluate the dissolution rates $\left(\mu \mathrm{g} . \mathrm{cm}^{-2}\right.$.day $\left.{ }^{-1}\right)$ of the rosin and the copper release rate, a jar test system was set up and adapted. Polyvinyl chloride tubes with a diameter and delimited area of $6 \mathrm{~cm}$ and $157 \mathrm{~cm}^{2}$, respectively, were used in the test. The polyvinyl chloride tube surface was prepared by grinding with silicon carbide paper (grade number 150), followed by immersion in methyl ethyl ketone for 15 minutes and drying. After surface preparation, the polyvinyl chloride tubes were painted.

Artificial seawater (ASW) was prepared according to standard ASTM D1141-9828 in six jar-test (Milan, Brazil) glass beakers (1 L each). The painted polyvinyl chloride tubes were fitted in the jar-test shaft and immersed in ASW. The rotation speed of the shaft was set at $60 \mathrm{rpm}^{29}$. The glass beakers were covered with a sealing film (Parafilm, USA) to avoid contamination.

For the calculation of the rosin dissolution rate, polyvinyl chloride tubes were removed from the ASW, rinsed with deionized water and dried in a vacuum oven $\left(60^{\circ} \mathrm{C}\right)$ until a constant weight. The rosin dissolution rate was calculated by a gravimetric method.

The amount of copper $\left(\mathrm{mg} \mathrm{L}^{-1}\right)$ released in the ASW was determined by flame atomic absorption spectrometry (FAAS) using an absorption spectrometer (CHAMA 3300, Perkin Elmer, USA). All glassware was immersed in $10 \%(\mathrm{v} / \mathrm{v})$ nitric acid for $24 \mathrm{~h}$ and rinsed three times with deionized water before use.

\subsection{Preparation and composition of the coatings}

All paints were prepared using a Dispermat N1 (VMAGetzmann GMBH of Reichshof, Germany) disperser with a Cowles disk and jacketed reactor. Initially, the resin, additives and approximately $70 \mathrm{~mL}$ of MEK were added into the reactor. The mixture was dispersed for 10 minutes to 
homogenize before pigment addition. The resulting coating was dispersed at $3000 \mathrm{rpm}$ for 1 hour. After dispersion of the coating, pigments were milled using a Dispermat SL-12 ball mill (VMA- Getzmann GMBH of Reichshof, Germany). The solvent was also added during this process. The size of the particles in the dispersed paint, evaluated according to the fineness of the grind gauge, was between 6 and 7 Hegman (25-15 $\mu \mathrm{m})$. Finally, the solvent was added to reach the desired viscosity.

Three coatings (hereafter denoted $E P_{1}, E P_{2}$ and $R O_{1}$ ) were formulated with two different binders (epoxy and rosin, respectively). The composition of each coating is detailed in Table 1 . The epoxy resin used for $E P_{1}$ and $E P_{2}$ was previously employed to formulate other antifouling coatings ${ }^{30}$. This epoxy resin becomes porous in a marine environment, improving contact between water and the pigment $^{30}$.

The pigment volume concentration $(P V C)$ of the formulated antifouling paint was kept between 38 and 42 vol. \%; this value typically varied between 30 and 45 vol. $\%^{31,32}$. Thus, the PVC must be high enough to create a porous network to increase the antifouling efficiency ${ }^{31}$. It should be noted that, if the $P V C$ is lower than $30 \mathrm{vol} \%$, the polishing rate becomes too slow ${ }^{31,32}$.

\subsection{Steel panel preparation}

AISI 1010 steel panels $(25 \mathrm{~cm} \times 20 \mathrm{~cm} \times 1 \mathrm{~mm})$ were previously degreased with acetone, polished with sandpaper (grain size \#150), rinsed with deionized water and degreased again. After surface preparation, the two sides of each panel were painted with one layer (thickness: $41 \pm 3 \mu \mathrm{m}$ ) of anticorrosive primer.

The commercial and formulated antifouling coatings were applied on one side of the panel and edges. All panels were painted with a brush. The film thickness was measured with a Byko-7500 test unit (BYK Gardner, Germany). Measurements were repeated eight times in different areas of the sample and the mean and standard deviation were calculated. The average thickness of the commercial, $E P_{l}$, $E P_{2}$ and $R O_{1}$ antifouling coatings are shown in Table 2.

\subsection{Assays in a natural marine environment}

Painted panels were immersed in an open channel of the Tramandaí River (2958'35.37', 5S, 5007'25.51'’ W) leading to the Atlantic Ocean (approximately $400 \mathrm{~m}$ from the ocean) in Brazil. This environment presents great variation in the salinity, $\mathrm{pH}$ and temperature of the water according to the season. Furthermore, salinity also varies daily ${ }^{33}$ around 2.5 wt. $\% \mathrm{NaCl}$.

Before immersion, painted panels were fixed with nylon straps on a polyvinyl chloride support. Blank panels (anticorrosive primer only) were used as the control and immersed under the same conditions. According to standard ASTM D3623 ${ }^{34}$ and Bellotti et al. ${ }^{17}$, the support was immersed approximately $60 \mathrm{~cm}$ deep. The degree of fouling attachment was evaluated every month and distances less than $1.3 \mathrm{~cm}$ from the edge of samples were not considered ${ }^{17,34}$. The antifouling efficiency of the coating was carried out according to the fouling coverage area. A value of $100 \%$ means complete coverage of the panel by fouling and $0 \%$ means the absence of fouling on the entire panel ${ }^{35}$.
Table 1. Coating compositions.

\begin{tabular}{|c|c|c|c|}
\hline Coating & Components & Vol.\% & $\operatorname{PVC}(\%)$ \\
\hline \multirow{4}{*}{$E P_{1}$} & Epoxy resin & 35.20 & \multirow{4}{*}{42} \\
\hline & Copper dodecanoate & 29.48 & \\
\hline & Additives $^{\mathrm{a}}$ & 5.82 & \\
\hline & MEK $^{\mathrm{b}}$ & 29.40 & \\
\hline \multirow{5}{*}{$E P_{2}$} & Epoxy resin & 36.80 & \multirow{5}{*}{38} \\
\hline & Copper dodecanoate & 6.10 & \\
\hline & $\mathrm{TiO}_{2+}$ chalk & 19.40 & \\
\hline & Additives $^{\mathrm{a}}$ & 6.00 & \\
\hline & $\mathrm{MEK}^{\mathrm{b}}$ & 30.60 & \\
\hline \multirow{3}{*}{$R O_{1}$} & Rosin & 28.80 & \multirow{3}{*}{41} \\
\hline & Copper dodecanoate & 20.30 & \\
\hline & $\mathrm{MEK}^{\mathrm{b}}$ & 50.80 & \\
\hline
\end{tabular}

a $10 \%$ BYK 410 and $90 \%$ Disperbyk 2070 (w/w). ${ }^{\text {IInitial amount of solvent }}$ used in the dispersion and grinding of pigments.

Table 2. Paints used on steel panels and dry film thickness.

\begin{tabular}{cc}
\hline Coating & Thickness $(\boldsymbol{\mu m})$ \\
\hline Anticorrosive primer (blank) & $41 \pm 3$ \\
Commercial & $229 \pm 13$ \\
$E P_{1}$ & $268 \pm 15$ \\
$E P_{2}$ & $248 \pm 17$ \\
$R O_{1}$ & $258 \pm 18$ \\
\hline
\end{tabular}

\section{Results and Discussion}

\subsection{Pigment characterization}

The FTIR spectra of dodecanoic acid and the prepared copper dodecanoate pigment are shown in Figure 1. For dodecanoic acid (Figure 1a), absorption bands at 2918 and $2853 \mathrm{~cm}^{-1}$ were attributed to $\mathrm{C}-\mathrm{H}$ stretching vibrations while the bands at 1702 and $940 \mathrm{~cm}^{-1}$ were assigned to the $\mathrm{C}=\mathrm{O}$ stretching and $\mathrm{OH}$-deformation of the carboxyl moiety, respectively ${ }^{36,37}$. The $\mathrm{CH}_{2}$ bending deformation at $721 \mathrm{~cm}^{-1}$, which is characteristic of the saturated chain in fatty acids ${ }^{27}$, appears in the two spectra. Figure $1 \mathrm{~b}$ shows two new absorption bands at 1445 and $1586 \mathrm{~cm}^{-1}$ (symmetric and asymmetric $\mathrm{COO}^{-}$, respectively), which reflect the interaction between copper ions and carboxylate groups ${ }^{36}$.

The X-ray diffractogram of copper dodecanoate is displayed in Figure 2. The region between a $2 \theta$ angle of $2^{\circ}$ and $15^{\circ}$ shows reflections of the (001) plane (i.e. up to fourthorder), indicating the existence of a lamellar structure ${ }^{36}$. The XRD diffraction pattern is fully consistent with those reported for metal dodecanoates ${ }^{27,36}$.

Figures $3 \mathrm{a}$ and $3 \mathrm{~b}$ show the thermogravimetric curves of dodecanoic acid and copper dodecanoate, respectively. Dodecanoic acid presented one decomposition decay, which begins at around $150^{\circ} \mathrm{C}$. After the weight loss process, the residual material detected at $600^{\circ} \mathrm{C}$ was practically non-existent. The thermogravimetric curve of copper dodecanoate indicates that the weight loss process started at approximately $210^{\circ} \mathrm{C}$. The DTGA curves indicate that the decomposition involved two peaks whose maximum rates occurred at $287^{\circ} \mathrm{C}$ and $326^{\circ} \mathrm{C}$. At $400^{\circ} \mathrm{C}$, metallic 
copper was the main residue of the char. At $800^{\circ} \mathrm{C}$, the residual material, which corresponds to metallic copper, was approximately $19 \%$ of the initial weigh, corroborating the formation of the pigment.

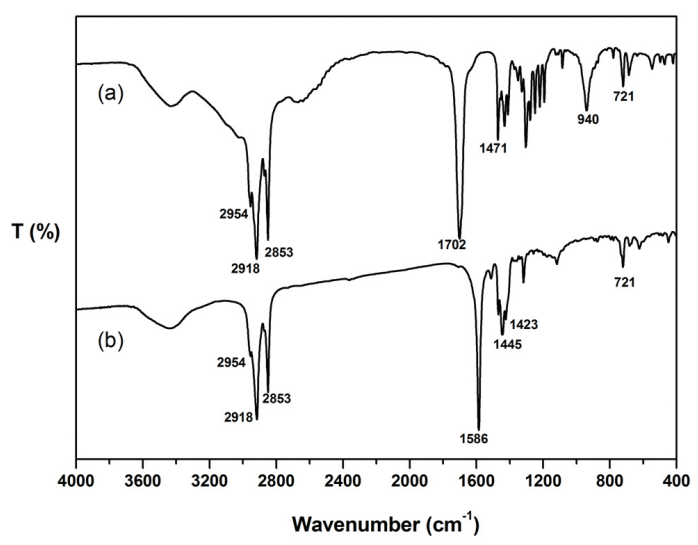

Figure 1. FTIR spectra of (a) dodecanoic acid and (b) copper dodecanoate.

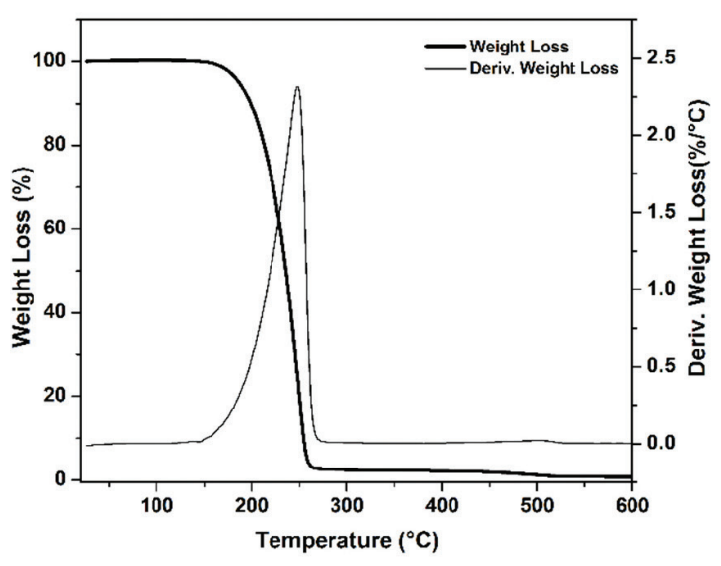

(a)
The DSC curves of dodecanoic acid and the copper dodecanoate pigment are displayed in Figure $4 \mathrm{a}$ and Figure $4 b$, respectively. The melting point of dodecanoic acid $\left(\sim 45^{\circ} \mathrm{C}\right)$ increased upon complexation with copper to

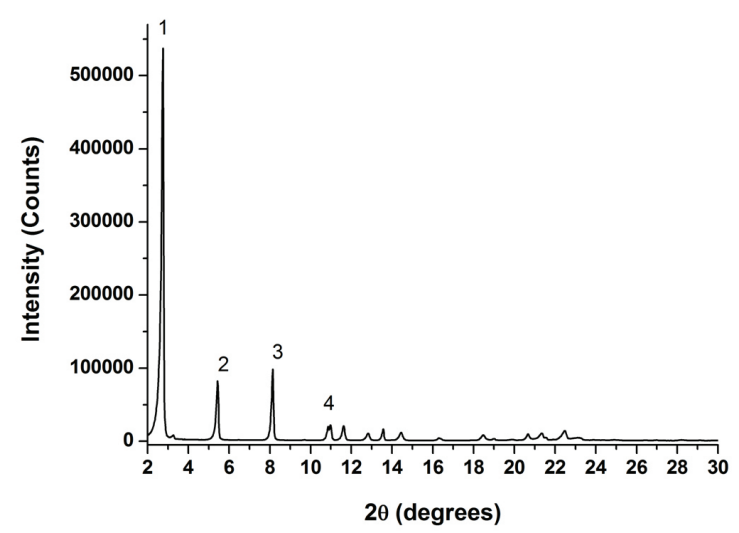

Figure 2. XRD pattern of copper dodecanoate.

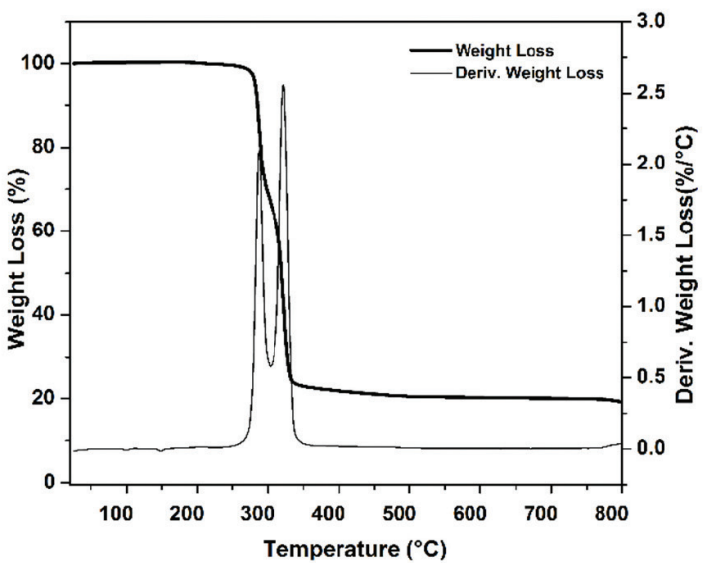

(b)

Figure 3. Thermogravimetric curves of (a) dodecanoic acid and (b) copper dodecanoate.

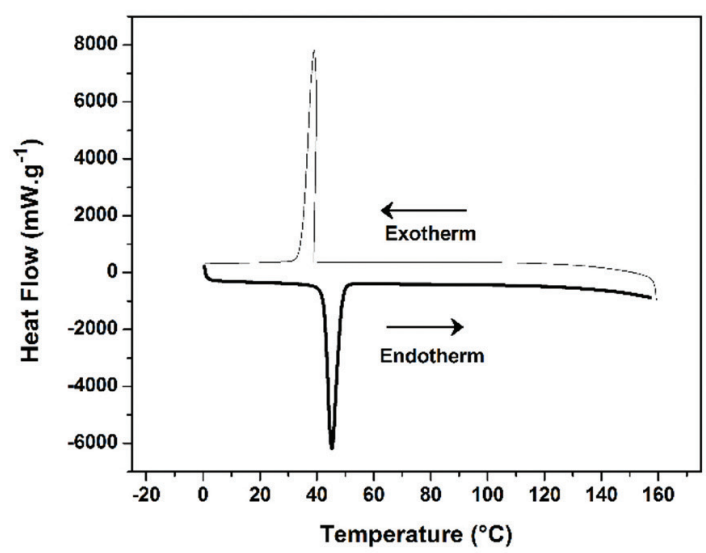

(a)

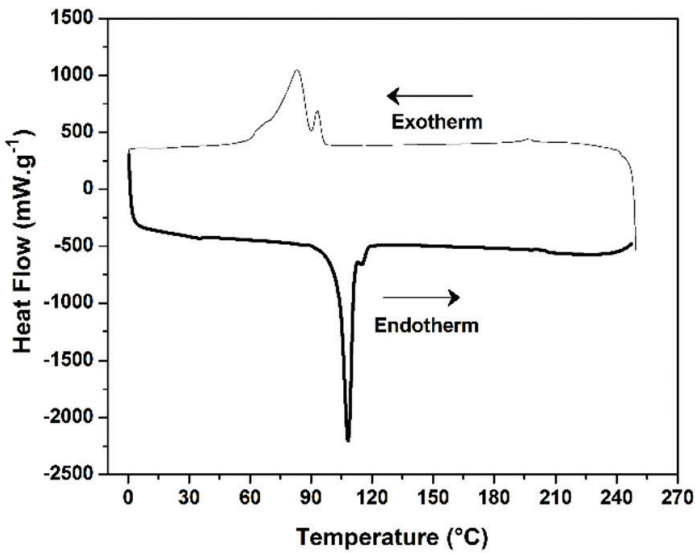

(b)

Figure 4. Heating and cooling DSC thermograms of (a) dodecanoic acid and (b) copper dodecanoate. 
form the copper dodecanoate pigment $\left(110^{\circ} \mathrm{C}\right)$, which is in agreement with the literature ${ }^{27,38}$.

\subsection{Rosin dissolution rate}

Colophony or rosin is a natural resin extracted from the gum of the pine tree. Generally, rosin is composed of about $85-90 \%$ acidic material and $15-10 \%$ neutral substances. Carboxyl groups react with the potassium and sodium ions in sea water, forming soluble salts (rosinates) ${ }^{39}$.

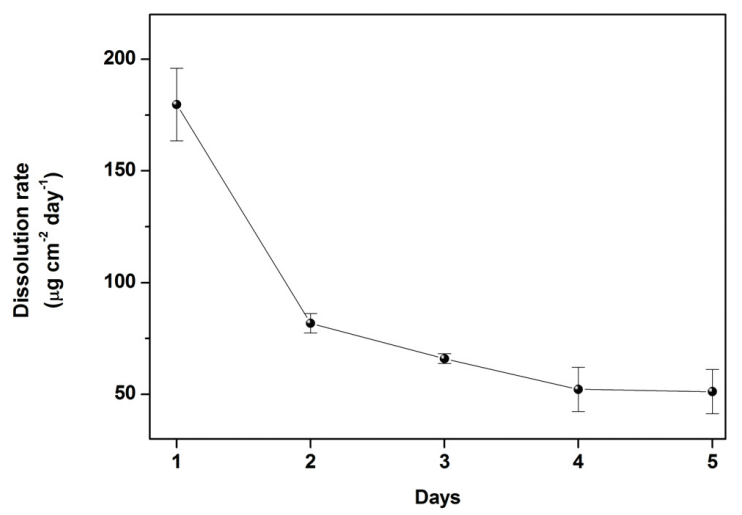

Figure 5. Rosin dissolution rates in artificial seawater against the immersion time. Error bars refer to the standard deviation (SD) derived from three independent measurements.
In order to evaluate the performance of rosin when used in antifouling paints, a dissolution test was carried out. Figure 5 shows the rosin dissolution rates in $\mu \mathrm{g} . \mathrm{cm}^{-2}$. day $^{-1}$, along with the standard deviation (SD) from three independent measurements. As can be seen, the dissolution rate of rosin was about $180 \mu \mathrm{g} . \mathrm{cm}^{-2}$. day ${ }^{-1}$ after one day of immersion, reaching a value of approximately $50 \mu \mathrm{g} . \mathrm{cm}^{-2}$. day $^{-1}$ in four days. This reduction in the dissolution rate, which is consistent with that reported in previous studies $^{1,39,40}$, can be attributed to oxidation of the surface and the formation of insoluble rosinate salts ${ }^{39}$. According to Yebra et al. ${ }^{39}$, the solvent trapped in the rosin film was found to contribute to the high dissolution rate observed after one day of immersion.

\subsection{Natural marine environment tests}

In order to examine the influence of the matrix on antifouling efficiency, the $R O_{1}$ and $E P$, coatings were tested by immersing painted steel panels in a natural marine environment.

Figure 6 shows the photographs of painted panels before immersion test. The photographs displayed in Figure 7 indicate that, after four months of immersion, the antifouling efficiency was higher for $E P_{1}$ than for $R O_{l}$. In the latter, $30 \%$ of the total area was covered by fouling organisms (Figure $7 \mathrm{~d}$ ); this amount increased to $60 \%$ on the blank panel (Figure $7 \mathrm{a}$ ). In contrast, no

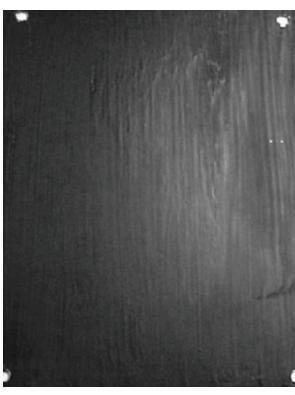

(a)

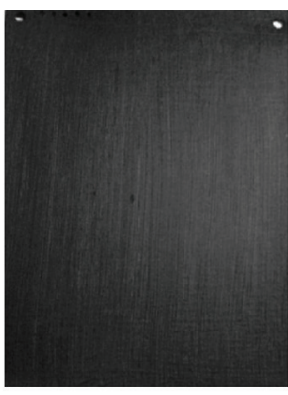

(b)

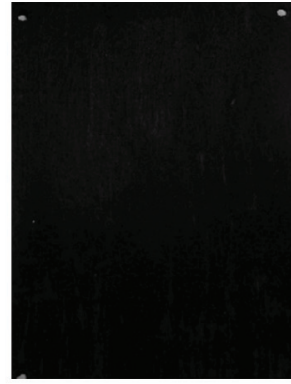

(c)

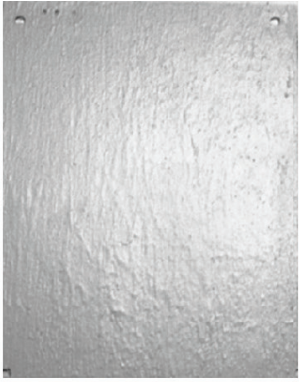

(d)

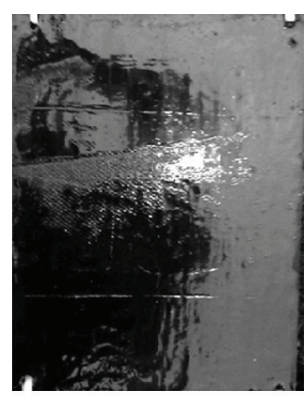

(e)

Figure 6. Photographs of steel panels before immersion tests: (a) blank; (b) commercial antifouling coating; (c) $E P_{l}$; (d) $E P_{2}$; and (e) $R O_{l}$. Dimensions of each steel panel: $25 \mathrm{~cm} \times 20 \mathrm{~cm} \times 1 \mathrm{~mm}$.

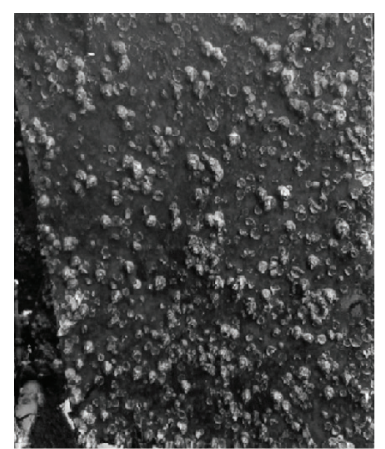

(a)

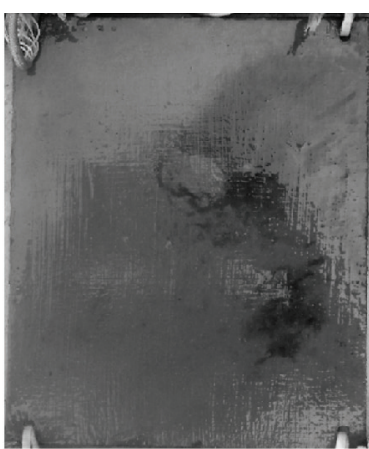

(b)

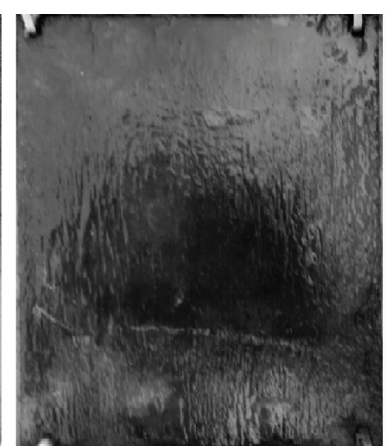

(c)

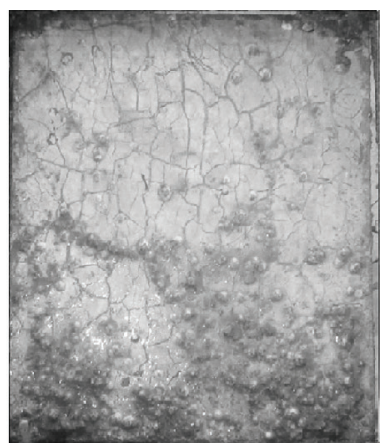

(d)

Figure 7. Photographs of steel panels immersed in a natural water environment for four months: (a) blank; (b) commercial antifouling coating; (c) $E P_{l}$; and (d) $R O_{l}$. Dimensions of each steel panel: $25 \mathrm{~cm} \times 20 \mathrm{~cm} \times 1 \mathrm{~mm}$. 


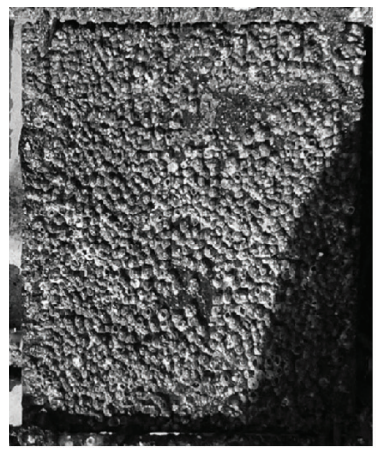

(a)

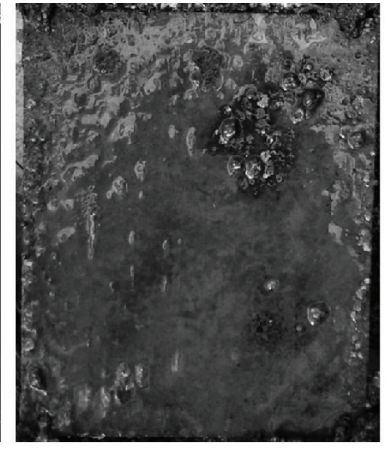

(b)

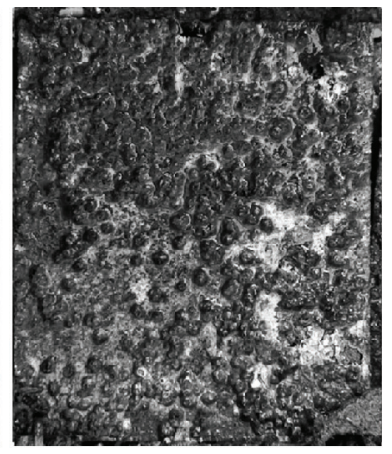

(c)

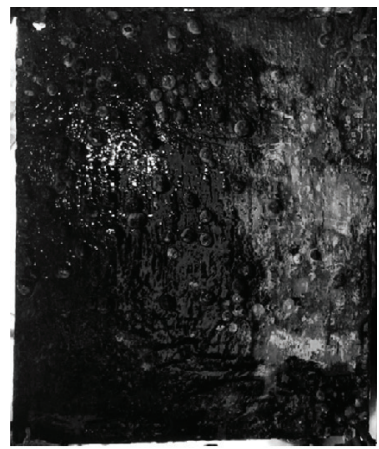

(d)

Figure 8. Photographs of steel panels immersed in a natural water environment for 12 months: (a) blank; (b) commercial antifouling coating; (c) $E P_{2}$; and (d) $E P_{l}$. Dimensions of each steel panel: $25 \mathrm{~cm} \times 20 \mathrm{~cm} \times 1 \mathrm{~mm}$.

trace of attached fouling organisms was detected with the commercial and $E P$, coatings (Figures $7 \mathrm{~b}$ and $7 \mathrm{c}$, respectively). The rosin coating $R O$, showed cracks on the surface, and barnacles were essentially attached at these places. This feature suggests that the adherence of rosinbased coatings should be improved using, for example, co-binders and plasticizers, which should be selected considering the chemical nature of the pigments and the required dissolution rates ${ }^{39,40}$.

The influence of the concentration of copper dodecanoate in the formulations was also examined. Thus, the content of copper dodecanoate was significantly lower in $E P_{2}$ than in $E P_{l}$. Photographs comparing the antifouling efficiency of $E P_{2}, E P_{1}$ and the commercial coating with the blank after 12 months of immersion are displayed in Figure 8.

The panel coated with $E P_{2}$ showed $75 \%$ of the total area covered by fouling organisms (Figure $8 \mathrm{c}$ ), while this parameter was $95 \%$ for the blank panel (Figure 8a). Panels painted with $E P_{l}$ (Figure 8d) and the commercial antifouling coating (Figure $8 \mathrm{~b}$ ) presented lower amounts of adhered fouling organisms (i.e. $7 \%$ and $4 \%$, respectively). These results clearly indicate that the antifouling activity of the formulated epoxy coatings increases with the concentration of copper dodecanoate (Table 1).

In order to evaluate the amount of copper released by the more efficient antifouling coatings, release tests were performed for both the commercial and $E P_{1}$ coatings. After 20 days, the total copper concentration leached from the $E P_{l}$ coating was only $0.053 \mathrm{mg} \mathrm{L}^{-1}$; this was considerably higher at $0.213 \mathrm{mg} \mathrm{L}^{-1}$ for the commercial coating. Accordingly, the amount of eliminated copper was $\sim 75 \%$ less in the epoxy formulation developed in this work than in the commercial coating, which represents a very significant reduction in marine contamination.

\section{Conclusions}

The FTIR, XRD and thermal analyses demonstrated the synthesis of a copper dodecanoate pigment. The performance of the epoxy- and rosin-based coatings, which incorporated copper dodecanoate as an antifouling pigment, was tested. The antifouling efficiency was found to be higher for the epoxy than for the rosin coating. On the other hand, the antifouling efficiency of the epoxy coating increased with the concentration of copper dodecanoate. After 12 months of immersion in natural sea water, panels painted with the copper dodecanoate-containing epoxy coating accumulated as little fouling as those painted with the commercial coating. Moreover, the antifouling paint developed in this work by combining the epoxy resin with copper dodecanoate showed a drastic reduction in copper release $(73.5 \%)$ with respect to the commercial paint. This is a very striking result since it allows us to conclude that application of this pigment produces similar, or even better, antifouling efficiency as those used in commercial coatings, but with a significantly decreased negative impact of these chemicals on the marine environment, especially in harbors.

\section{Acknowledgments}

The authors thank the Brazilian government agencies CNPq and CAPES (process BEX 13736124) which provided the financial support for this study and the scholarship for R.S Peres. Financial support for E.A. and C.A. comes from MICINN and FEDER (MAT2012-34498), and the Generalitat de Catalunya (research group 2009 SGR 925) is gratefully acknowledged. Support for the research of C.A. was received through the "ICREA Academia" prize for excellence in research funded by the Generalitat de Catalunya. 


\section{References}

1. Redfield AC and Hutchins LW. Problems of fouling. In: Woods Hole Oceanographic Institution. Marine fouling and its prevention. Menasha: George Banta Publishing Co.; 1952. p. 3-20.

2. Myers JH, Gunthorpe L, Allinson G and Duda S. Effects of antifouling biocides to the germination and growth of the marine macroalga, Hormosira banksii (Turner) Desicaine. Marine Pollution Bulletin. 2006; 52(9):1048-1055. http:// dx.doi.org/10.1016/j.marpolbul.2006.01.010

3. Almeida E, Diamantino TC and De Sousa O. Marine paints: the particular case of antifouling paints. Progress in Organic Coatings. 2007; 59(1):2-20. http://dx.doi.org/10.1016/j. porgcoat.2007.01.017

4. Yebra DM, Kiil S and Dam-Johansen K. Antifouling technology_past, present and future steps towards efficient and environmentally friendly antifouling coatings. Progress in Organic Coatings. 2004; 50(2):75-104. http://dx.doi. org/10.1016/j.porgcoat.2003.06.001

5. Senda T. International trends in regulatory aspects. In: Arai T, Harino H, Ohji M and Langston W, editors. Ecotoxicology of antifouling biocides. Tokyo: Springer; 2009. p. 23-38. http:// dx.doi.org/10.1007/978-4-431-85709-9_2

6. Lewandowski $\mathrm{Z}$ and Beyenal $\mathrm{H}$. Mechanisms of microbially influenced corrosion. In: Flemming H-C, Murthy PS, Venkatesan R and Cooksey KE, editors. Marine and industrial biofouling. Berlin: Springer; 2009. p. 35-64. http://dx.doi. org/10.1007/978-3-540-69796-1_3

7. Readman JW. Development, occurrence and regulation of antifouling paint biocides: historical review and future trends. In: Konstantinou IK, editor. Antifouling paint biocides. Berlin: Springer; 2006. p. 1-16. http://dx.doi.org/10.1007/698_5_047

8. Pérez M, Blustein G, García M, del Amo B and Stupak M. Cupric tannate: a low copper content antifouling pigment. Progress in Organic Coatings. 2006; 55(4):311-315. http:// dx.doi.org/10.1016/j.porgcoat.2005.11.014

9. Hugues C, Bressy C and Margaillan A. Les différentes approches de protection marine antisalissure par peinture. Annales de Chimie - Science des Matériaux. 2003; 28(3):91107. http://dx.doi.org/10.1016/S0151-9107(03)00055-2

10. Song YC, Woo JH, Park SH and Kim IS. A study on the treatment of antifouling paint waste from shipyard. Marine Pollution Bulletin. 2005; 51(8-12):1048-1053.

11. Fay F, Linossier I, Langlois V, Haras D and Vallee-Rehel K. SEM and EDX analysis: two powerful techniques for the study of antifouling paints. Progress in Organic Coatings. 2005; 54(3):216-223. http://dx.doi.org/10.1016/j. porgcoat.2005.05.005

12. Fent K. Ecotoxicology of organotin compounds. Zurich: Swiss Federal Institute for Environmental Science and Technology (EAWAG); 1994.

13. Godoi AFL, Favoreto R and Santiago-Silva M. Contaminação ambiental por compostos organoestânicos. Quimica Nova. 2003; 26:708-716. http://dx.doi.org/10.1590/S010040422003000500015

14. Alzieu C. Environmental impact of TBT: the French experience. Science of the Total Environment. 2000; 258(12):99-102. http://dx.doi.org/10.1016/S0048-9697(00)00510-6

15. Champ MA. Economic and environmental impacts on ports and harbors from the convention to ban harmful marine anti-fouling systems. Marine Pollution Bulletin. 2003; 46(8):935-940. http://dx.doi.org/10.1016/S0025-326X(03)00106-1
16. Oikonomou EK, Iatridi Z, Moschakou M, Damigos $P$, Bokias G and Kallitsis JK. Development of $\mathrm{Cu}^{2+}$ - and/or phosphonium-based polymeric biocidal materials and their potential application in antifouling paints. Progress in Organic Coatings. 2012; 75(3):190-199. http://dx.doi.org/10.1016/j. porgcoat.2012.04.019

17. Bellotti N, Deyá C, del Amo B and Romagnoli R. Antifouling paints with zinc "tannate". Industrial and Engineering Chemistry Research. 2010; 49(7):3386-3390. http://dx.doi. org/10.1021/ie9010518

18. Camail M, Humbert M, Margaillan A, Riondel A and Vernet JL. New acrylic titanium polymers: 1. Synthesis and characterisation of new titanium trialkoxide methacrylate monomers prepared via the esterification of methacrylic acid by titanium tetraalkoxides. Polymer. 1998; 39(25):6525-6531. http://dx.doi.org/10.1016/S0032-3861(98)00145-1

19. Flemming $\mathrm{C}$ and Trevors J. Copper toxicity and chemistry in the environment: a review. Water, Air and Soil Pollution. 1989; 44(1-2):143-158. http://dx.doi.org/10.1007/ BF00228784

20. Voulvoulis N, Scrimshaw MD and Lester JN. Comparative environmental assessment of biocides used in antifouling paints. Chemosphere. 2002; 47(7):789-795. http://dx.doi. org/10.1016/S0045-6535(01)00336-8

21. Desbois A and Smith V. Antibacterial free fatty acids: activities, mechanisms of action and biotechnological potential. Applied Microbiology and Biotechnology. 2010; 85(6):1629-1642. http://dx.doi.org/10.1007/s00253-009-2355-3

22. Bissinger BW and Roe RM. Tick repellents: past, present, and future. Pesticide Biochemistry and Physiology. 2010; 96(2):6379. http://dx.doi.org/10.1016/j.pestbp.2009.09.010

23. Walters DR, Walker RL and Walker KC. Lauric acid exhibits antifungal activity against plant pathogenic fungi. Journal of Phytopathology. 2003; 151(4):228-230. http://dx.doi. org/10.1046/j.1439-0434.2003.00713.x

24. Wu J-T, Chiang Y-R, Huang W-Y and Jane W-N. Cytotoxic effects of free fatty acids on phytoplankton algae and cyanobacteria. Aquatic Toxicology. 2006; 80(4):338-345. http:// dx.doi.org/10.1016/j.aquatox.2006.09.011

25. Bergsson G, Arnfinnsson J, Karlsson SM, Steingrímsson Ó and Thormar $\mathrm{H}$. In vitro inactivation of Chlamydia trachomatis by fatty acids and monoglycerides. Antimicrobial Agents and Chemotherapy. 1998; 42(9):2290-2294.

26. Bergsson G, Arnfinnsson J, Steingrímsson Ó and Thormar H. Killing of Gram-positive cocci by fatty acids and monoglycerides. Apmis. 2001; 109(10):670-678. http://dx.doi. org/10.1034/j.1600-0463.2001.d01-131.x

27. Lisboa FS, Gardolinski JEF, Cordeiro CS, Wypych F. Layered metal laurates as active catalysts in the methyl/ ethyl esterification reactions of lauric acid. Journal of the Brazilian Chemical Society. 2012; 23(1):39-45. http://dx.doi. org/10.1590/S0103-50532012000100008

28. American Society for Testing and Materials - ASTM. D114198: Standard Practice for the Preparation of Substitute Ocean Water. ASTM; 2013.

29. American Society for Testing and Materials - ASTM. D644206: Standard Test Method for Determination of Copper Release Rate From Antifouling Coatings in Substitute Ocean Water. ASTM; 2006.

30. Baldissera AF. Development of unconventional antifouling paint to protect ships and steel structures. [Ph.D. Thesis]. Porto Alegre: Universidade Federal do Rio Grande do Sul; 2008. 
31. Kiil S, Weinell CE, Pedersen MS and Dam-Johansen K. Mathematical modelling of a self-polishing antifouling paint exposed to seawater: a parameter study. Chemical Engineering Research and Design. 2002; 80(1):45-52. http://dx.doi. org/10.1205/026387602753393358

32. Gitlitz MH and Leiner HH. Erodible ship-bottom paints for control of marine pouling. U.S. Patent 4,593,055; 1986.

33. Kapusta SC, Würding NL, Benvenuti CE and Ozorio CP. Meiofauna structure in Tramandaí-Armazém estuary (South of Brazil). Acta Limnologica Brasiliensia. 2005; 17(4):349-359.

34. American Society for Testing and Materials - ASTM. D362378a: Standard Test Method for Testing Antifouling Panels in Shallow Submergence. ASTM; 2004.

35. American Society for Testing and Materials - ASTM. D699005: Standard Practice for Evaluating Biofouling Resistance and Physical Performance of Marine Coating Systems. ASTM; 2011.

36. Chakradhar RPS, Dinesh Kumar V, Shivakumara C, Rao $\mathrm{JL}$ and Basu BJ. Characterisation of microstructure and evaluation of optical and EPR properties of superhydrophobic copper dodecanoate films. Surface and Interface
Analysis. 2012; 44(4):412-417. http://dx.doi.org/10.1002/ sia.3818

37. Jart A. The infrared absorption spectra of some monounsaturated and saturated fatty acids and esters. Acta Chemica Scandinavica. 1960; 14:1867-1878. http://dx.doi.org/10.3891/ acta.chem.scand.14-1867

38. Haynes WM, Lide DR and Bruno TJ. CRC Handbook of chemistry and physics 2012-2013. Boca Raton: CRC Press; 2012.

39. Yebra DM, Kiil S, Dam-Johansen K and Weinell C. Reaction rate estimation of controlled-release antifouling paint binders: Rosin-based systems. Progress in Organic Coatings. 2005; 53(4):256-275. http://dx.doi.org/10.1016/j. porgcoat.2005.03.008

40. Rascio VJD, Giúdice CA and del Amo B. Research and development of soluble matrix antifouling paints for ships, offshore platforms, and power stations - A review. Corrosion Reviews. 1988; 8(1-2):87-153. http://dx.doi.org/10.1515/ CORRREV.1988.8.1-2.87 